\title{
Perforating eye injuries caused by darts
}

\author{
M D COLE AND D SMERDON \\ From the Birmingham and Midland Eye Hospital
}

SUMMARY We have reviewed 19 patients with dart-induced perforating eye injuries. Fourteen of the injuries were in childhood. A poor visual outcome was common, not only from the injury directly but also from irreversible amblyopia or endophthalmitis. Preventive measures are considered.

Darts are responsible for the largest single group of childhood perforating eye injuries.' To find ways in which this type of injury can be prevented, we have analysed a group of patients who have sustained dartinduced perforating eye injuries. Our aims were to determine the incidence, mode, and type of injury and the eventual visual outcome.

\section{Materials and methods}

Theatre registers from the Birmingham and Midland Eye Hospital were used to identify all cases of perforating eye injuries between 1 September 1977 and 30 June 1985. The corresponding medical records were examined.

All patients with dart injury were recalled for examination so that the histories could be verified, and the final visual outcome determined. This gave a minimum of 12 months' follow-up for the 15 who attended.

The following details were recorded: Age and sex, place injury occurred, time taken to reach the casualty department, mode of injury, part of dart involved, pattern of injury, and outcome.

\section{Results}

The records of 436 patients were reviewed. They represented a $97 \%$ retrieval. Of these patients 375 patients sustained perforating eye injuries, 19 of which were caused by darts $(5 \%)$. Of these, 15 attended for reappraisal $(80 \%)$.

Correspondence to M D Cole, FRCS, Birmingham and Midland Eye Hospital, Church Street, Birmingham B3 2NS.
The results are summarised in Tables 1 and 2 and analysed below.

There were $78(20 \cdot 8 \%)$ childhood injuries (defined as those injuries occurring under the age of 14 years), 14 of which $(18 \%)$ were caused by darts.

The male to female ratio for dart injuries was $2 \cdot 8: 1$ $(14: 5)$.

Of the 19 injuries, 18 occurred in the patient's or a friend's home. One injury occurred in a boys' club.

We looked specifically at the delay between injury and hospital attendance and found that five patients took longer than 12 hours to attend. All of these

Table 1 Casehistory

\begin{tabular}{rrlllll}
\hline Patient no. & Age & Sex & Eye & Dart end & Cause & Delay* \\
\hline 1 & 7 & M & R & Point & Playing & - \\
2 & 3 & M & R & Point & Playing & $?$ \\
3 & 4 & M & R & Stem & Pull out & - \\
4 & 4 & F & R & Point & Throw & $48 \mathrm{~h}$ \\
5 & 15 & M & R & Flight & Pull out & $18 \mathrm{~h}$ \\
6 & 4 & F & R & Point & Threw & $?$ \\
7 & 17 & M & R & Point & Threw & - \\
8 & 10 & M & L & ? & Pull out & $?$ \\
9 & 3 & F & R & Point & Threw & - \\
10 & 7 & M & L & Point & Threw & $12 \mathrm{~h}$ \\
11 & 18 & F & R & Point & Pull out & $12 \mathrm{~h}$ \\
12 & 6 & M & L & Point & Playing & $?$ \\
13 & 9 & M & R & Flight & Aiming & $?$ \\
14 & 24 & M & R & Flight & Pull out & $24 \mathrm{~h}$ \\
15 & 11 & M & R & Flight & Pull out & - \\
16 & 10 & M & R & ? & Rebound & $16 \mathrm{~h}$ \\
17 & 2 & M & L & Flight & Pull out & $?$ \\
18 & 3 & F & L & ? & Play & - \\
19 & 12 & M & R & Flight & Pull out & - \\
\hline
\end{tabular}

${ }^{*}$ Delay quoted if $\geqslant 12 \mathrm{hr}$. 
Table 2 Injury and outcome

\begin{tabular}{llllll}
\hline $\begin{array}{l}\text { Patient } \\
\text { no. }\end{array}$ & $\begin{array}{l}\text { Follow- } \\
\text { up,yr }\end{array}$ & $\begin{array}{l}\text { Lid } \\
\text { injury }\end{array}$ & $\begin{array}{l}\text { Wound } \\
\text { site }\end{array}$ & Complications & VA \\
\hline 1 & $0 \cdot 33$ & Upper & Sclera & Chorioretinal scar & $6 / 12$ \\
2 & $0 \cdot 66$ & Nil & Limbus & $?$ & $?$ \\
3 & 8 & Nil & Cornea & Esotropia/amblyopia & HM \\
4 & 8 & Nil & Limbus & Chorioretinal scar & $6 / 6$ \\
5 & 7 & Nil & Cornea & - & $6 / 6$ \\
6 & 7 & Nil & Cornea & Esotropia/amblyopia & CF \\
7 & 7 & Upper & Sclera & - & $6 / 6$ \\
8 & $1 \cdot 33$ & Nil & Cornea & - & $6 / 5$ \\
9 & 7 & Nil & Cornea & Amblyopia & HM \\
10 & 7 & Upper Cornea & Esotropia/phthisis & NPL \\
11 & 6 & Nil & Cornea & $6 / 6$ \\
12 & $0 \cdot 06$ & Upper & Cornea & - & $6 / 6$ \\
13 & 5 & Nil & Cornea & - & $6 / 5$ \\
14 & 4 & Nil & Cornea & - & $6 / 5$ \\
15 & 4 & Nil & Limbus & - & $6 / 5$ \\
16 & 3 & Nil & Cornea & Esotropia & $6 / 18$ \\
17 & 3 & Nil & Cornea & Amblyopia & $6 / 9$ \\
18 & 2 & Nil & Cornea & Exotropia/ambolyopia & $6 / 9$ \\
19 & $1 \cdot 5$ & Nil & Cornea & Vitrectomy/macular scar & $6 / 36$ \\
\hline
\end{tabular}

$\mathrm{HM}=$ hand movements. $\mathrm{NPL}=$ no perception of light.

patients felt that at the time the injury was not serious and attended only because of symptoms of blurred vision, watering, and pain in the eye.

There were eight self-inflicted injuries, seven of which occurred while pulling the dart out of the target (five dart boards, one calendar, and one toy elephant). This was caused by either pulling the flight end into the eye or by dropping the dart. One injury was caused by drawing the flight end of the dart into the eye while taking aim.

The dart was thrown by a friend or sibling in seven cases. One injury resulted from the dart rebounding off the board, and the remaining four resulted in an uncertain manner from childhood play.

There were nine injuries which resulted by the pointed end entering the eye and seven by the flight end (one with the flights removed). The remaining three patients did not know which end was responsible.

There were four whose injury was caused by the point penetrating the upper lid (two scleral and two corneal perforations).

The injuries were divided into 17 small $(4 \mathrm{~mm}$ or less) and 2 large $(>4 \mathrm{~mm})$ injuries. All these injuries were linear. There was no specific pattern to the wounds, except that flight-end injuries tended to have larger surface and smaller endothelial wounds. The perforations were mainly corneal (14), but three were limbal and two were scleral.

Significant lens injury was found in nine patients and insignificant injury in two (localised anterior subcapsular lens opacity, which did not progress or affect acuity). Of those with significant lens injury
Table 3 Results oflensectomy

\begin{tabular}{|c|c|c|c|c|c|c|}
\hline $\begin{array}{l}\text { Patient } \\
\text { no. }\end{array}$ & End & $\begin{array}{l}\text { Age } \\
(y r)\end{array}$ & Procedure & $C L$ & Amblyopia & $V A$ \\
\hline 3 & Flight & 3 & Secondary + AV & $C L(A b)$ & Amb. & $\mathrm{HM}$ \\
\hline 6 & Point & 4 & Secondary + AV & $\mathrm{CL}(\mathrm{Ab})$ & Amb. & $\mathrm{CF}$ \\
\hline 9 & Point & 3 & Secondary + PK & - & Amb. & HM \\
\hline 10 & Point & 7 & Secondary + AV & - & & NPL \\
\hline 11 & Point & 24 & Primary + AV & $\mathrm{CL}(\mathrm{Ab})$ & & $6 / 6$ \\
\hline 16 & $?$ & 10 & Primary + AV & CL & & $6 / 18$ \\
\hline 17 & Flight & 2 & Primary & $\mathrm{CL}$ & Amb. & $6 / 60$ \\
\hline 18 & $?$ & 3 & Secondary & IOL & Amb. & $6 / 9$ \\
\hline 19 & Flight & 12 & Primary + AV & $\mathrm{CL}$ & & $6 / 36$ \\
\hline
\end{tabular}

$\mathrm{AV}=$ anterior vitrectomy. $\mathrm{CL}=$ contact lens. $\mathrm{Ab}=$ abandoned.

$\mathrm{HM}=$ hand movements. $\mathrm{CF}=$ counting fingers. $\mathrm{NPL}=$ no perception of light.

four had a primary and five had a secondary lens extraction, with six requiring an anterior vitrectomy. N

Aphakic correction was by contact lens in six or patients (three later abandoned them), and one 3year-old child was corrected with an intraocular lens 0 inserted after secondary lensectomy. No correction was given to two patients, one awaiting penetrating $\vec{c}$ keratoplasty and one who developed endophthalmitis with phthisis bulbi (Table 3). Lens damage was $\overrightarrow{0}$ caused as often by the flight end as the pointed end of the dart.

We looked specifically at strabismus, amblyopia, and eventual visual acuity. A secondary horizontal squint was found in five patients (four convergent, one divergent). Amblyopia developed in five patients $\stackrel{\circ}{\circ}$ aged under 5 years after lens extraction which $\mathbb{2}$ required occlusion therapy. Of these patients four $\overrightarrow{\overrightarrow{0}}$ had contact lens correction, but all resulted in a poor 3 visual outcome $(<6 / 36)$. An intraocular lens was used $\subsetneq$ for a 3-year-old which gave a visual outcome of 6/9. There were peripheral chorioretinal scars in three patients. These did not cause secondary retinal problems and included both cases with scleral wounds.

Postoperative endophthalmitis ensued in two patients $(10 \cdot 5 \%)$. One eye became blind and

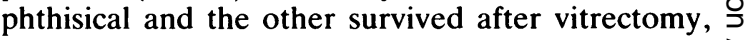
achieving a visual acuity of $6 / 36$. We were unable to $\frac{7}{0}$ establish whether the macular scar found subsequently was due to the original injury.

Table 4 Visual outcome

\begin{tabular}{ll}
\hline Visual acuity & No. of patients \\
\hline $6 / 5-6 / 6$ & 8 \\
$6 / 9-6 / 12$ & 1 (Amblyopic) \\
$6 / 18-6 / 24$ & 1 (?) \\
$6 / 36-6 / 60$ & $2(1$ Macular scar, 1 amblyopic) \\
$<6 / 60-P L$ & 3 (All amblyopic, one graft failure also) \\
NPL & 1 (Phthisis from endophthalmitis) \\
\hline
\end{tabular}

\section{旁言} (t) 
The eventual visual acuity of 16 patients with a follow-up of greater than 12 months was assessed (Table 4). A final acuity of $6 / 6$ or better was seen in eight patients. One had no perception of light and seven had acuities between these extremes; five had amblyopia, one had a macular scar, and in one the reason for a poor acuity was not explained satisfactorily.

\section{Discussion}

Various authors ${ }^{2-5}$ have included darts as a cause of perforating eye injury in children. Roper-Hall ${ }^{6}$ stressed that toys had proved to be unexpectedly dangerous, and we agree with this. Children are notorious for the wide variety of objects which they manage to stick in their eyes,' and it is difficult to pinpoint ways in which these injuries can be prevented. It is only the latest series of perforating eye injuries by Cole et al. ${ }^{1}$ that emphasises that darts are the commonest cause in children, as the present study confirms.

The perforations are usually small and the patient may not appreciate how serious the injury is, especially if the pointed end of the dart went through the eyelid. This may lead to delay in attending the casualty department, which contributes to the risk of endophthalmitis.

Amblyopia is a prominent factor in poor visual outcome. In this study 10 patients were aged under 8 and thus prone to developing amblyopia. All those under 8 who required lens surgery (excluding the patient who became blind from endophthalmitis) became amblyopic. This was reversed in only one patient, whose aphakia was corrected with an intraocular lens. Treatment was particularly unsatisfactory in one child who had both failed penetrating keratoplasty and failed trabeculectomy. Eagling ${ }^{7}$ also found that the perforating eye injuries in this age group requiring lens surgery usually suffered from irreversible amblyopia, even with immediate lens surgery (with or without an intraocular lens), as it is difficult to achieve clear media within two months of the injury.

Darts are capable of causing an injury with either end. Even with the flights removed the shaft can still cause injury. It is not generally appreciated how dangerous darts can be. This was shown by the two 17-year-old friends who threw darts directly at each other for fun (patient no. 7). However, the problem must be considered in perspective. Some five million people play darts regularly (Lowy SR, personal communication, 1986), and the game when played properly is very safe. All but one of the injuries occurred in the home, and 14 out of 19 were childhood injuries.

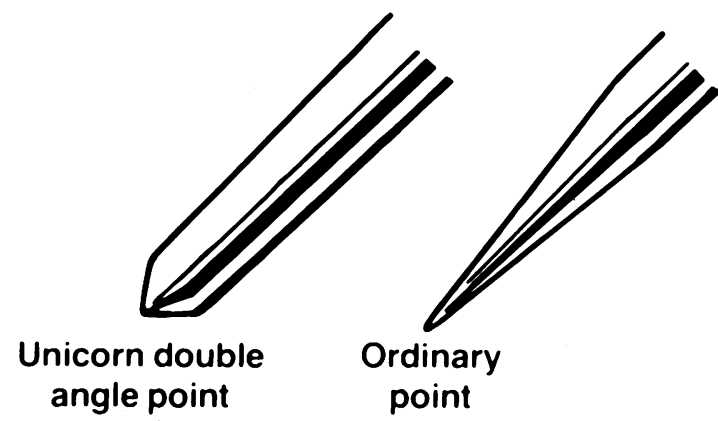

Fig. 1 Dart ends illustrating the safer point.

Preventive measures can help to reduce the incidence of injuries. The most recent example of this is the influence of seat belt legislation on perforating eye injuries. ${ }^{89}$

We consider that all adults, and especially parents, should be encouraged to consider darts an adult game. A major manufacturer of darts print in their catalogue to retailers (Lowy SR, personal communication, 1986): 'To our customers. Warning. Darts is an adult sport. It is dangerous for children to play without supervision. We recommend that a dealer should exercise discretion where any sale might result in children playing without adult supervision.' On every set of darts that they sell they print in six languages-English, French; German, Spanish, Arabic, and Japanese - the following: 'Darts is an adult sport. It is dangerous for children to play without supervision.'

Certain dart manufacturers design their dart points in such a way that they will penetrate the dartboard without difficulty but are much less likely to pierce the skin than a conventionally designed point (Fig. 1 ). This may influence the likelihood of perforation of the globe. In view of the rather surprising number of injuries caused by the flight end, it may be possible to design safer darts. Dart flights need to be fairly stiff to maintain a consistent trajectory, but they do not need to be sharp or pointed.

The British Standards Institution has published several standards that deal with the safety of toys (Hall AJ, personal communication, 1986). The following paragraph (3.2.2.10.3) applies to darts for children: 'The points of darts for children shall not be made of metal; points fitted with magnetic discs are permitted.'

We consider that this clause should include guidelines for the production of flights. As the British Standard is being revised, this survey has been submitted to the committee responsible for consideration.

The consumer unit of the Department of Trade and Industry has also studied the results of our survey 
(Loughlin TRJ, personal communication, 1986) and forwarded a copy to the British Sports and Allied Industries Federation, who represent dart manufacturers. The consumer unit has recommended that 'the packaging of adult darts should contain a warning against allowing children under 14 years to use them unsupervised.' They have also suggested that dart manufacturers 'should consider carefully the design of flights so that they avoid sharp tails and sharp points at the rear of the dart.'

CONCLUSION

Adult-type darts must not be considered as toys, and the unsupervised use of darts by children must be discouraged. Manufacturers must be encouraged to consider ocular safety when designing their darts.

We thank the consultants in the Birmingham and Midland Eye Hospital for permission to report their cases; and Miss E M Eagling and MRS J E Cole for their kind help and advice in the preparation of this paper.

\section{References}

1 Cole MD, Clearkin L, Dabbs T, Smerdon D. The scat-belt law and after. Br J Ophthalmol 1987; 71: 436-40.

2 Roper-Hall MJ. The treatment of ocular injuries. Trans Ophthalmol Soc UK 1959; 79: 57-69.

3 Johnson S. Perforating eye injuries: a five year study. Trans Ophthalmol Soc UK 1971; 91: 895-921.

4 Horan EC. Perforating eye injuries in Cork. Trans Ophthalmol Soc UK 1979; 97: 511-4.

5 Canavan YM, O'Flaherty MJ, Archer DB. A 10-year old survey of eye injuries in Northern Ireland, 1967-76. Br J Ophthalmol 1980; 64: 618-25.

6 Roper-Hall MJ. Injuries. In: Sorsby A, ed. Systemic ophthalmology. London: Butterworths, 1963.

7 Eagling EM. Perforating injuries of the eye. Br J Ophthalmol 1976; 60: 732-6.

8 Hall NF, Denning AM, Elkington AR, Cooper PJ. The eye and the seat in Wessex. BrJ Ophthalmol 1985; 69: 317-9.

9 Johnston PB, Armstrong MFJ. Eye injuries in Northern Ireland two years after seat belt legislation. Br J Ophthalmol 1986; 70: $460-2$.

Accepted for publication 18 May 1987. 